\title{
NEUTRON MONITOR RECORDS IN BROADER HISTORICAL CONTEXT
}

\author{
JÜRG BEER \\ Environmental Physics, EAWAG, CH-8600 Dübendorf, Switzerland
}

(Received 9 July 1999; accepted 22 January 2000)

\begin{abstract}
Man-made neutron monitors have provided a continuous detailed record of the cosmicray flux over only about the last 5 decades. Fortunately, nature operates its own detectors and offers the opportunity to extend the cosmic-ray records over much longer time scales. Two different types of 'natural detectors' can be distinguished. The first is based on long lived radionuclides that are produced by cosmic-ray interactions in the atmosphere and subsequently become stored in archives such as ice sheets or tree rings. The second type are rocks that are exposed to cosmic-rays at a certain time and from then on integrate the production of cosmogenic nuclides over the whole exposure time. The analysis of ${ }^{10} \mathrm{Be}$ in polar ice cores and ${ }^{14} \mathrm{C}$ in tree rings clearly reveals solar and geomagnetic modulation of the cosmic-ray flux on different time scales ranging from decades (11-year Schwabe cycle) to millennia.
\end{abstract}

\section{Introduction}

Cosmic-ray particles traveling through space and penetrating into the atmosphere of the Earth convey a wealth of important information about the cosmos, the galaxies, the stars, the distribution and composition of extraterrestrial matter, and galactic and intergalactic magnetic fields. In the vicinity of the Earth they are affected by the magnetic properties of the solar wind and the geomagnetic field. Neutron detectors positioned on different latitudes and altitudes monitor the incoming cosmic-ray flux with a high temporal resolution of minutes and are therefore well-suited to study short-term processes mainly related to solar activity. However, the total time span covered by man-made neutron monitors is rather limited. After the discovery of the cosmic-rays at the beginning of the 20th century it took another three decades until continuous measurements began. The earliest measurements were performed with ionisation chambers and by neutron monitors from 1950 onwards. In order to study long-term effects correspondingly longer cosmic-ray records are required and the question arises how such records can be made available. The goal of this paper is to show that nature provides two kinds of natural 'neutron detectors' which, to some extent, fulfill these requirements. After introducing the principles these natural neutron detectors are based on, we will discuss some examples to illustrate their potential and limitations. 
TABLE I

Properties of cosmogenic radionuclides (Masarik and Beer, 1999)

\begin{tabular}{llll}
\hline Nuclide & Half-life $(\mathrm{yr})$ & Targets & Prod. rate $\left(\mathrm{cm}^{-2} \mathrm{~s}^{-1}\right)$ \\
\hline${ }^{10} \mathrm{Be}$ & $1.51 \times 10^{6}$ & $\mathrm{~N}, \mathrm{O}$ & 0.018 \\
${ }^{14} \mathrm{C}$ & 5730 & $\mathrm{~N}$ & 2.0 \\
${ }^{36} \mathrm{Cl}$ & $3.08 \times 10^{5}$ & $\mathrm{Ar}$ & 0.0019 \\
\hline
\end{tabular}

\section{Cosmic-Ray Detectors}

State of the art man-made neutron monitors are devices that record the cosmic-ray flux by counting on-line the nuclear interactions that take place in the detector. In most cases, secondary particles produced in the atmosphere by primary cosmic-ray particles from space interact in the lead surrounding the counter which leads to the next step of fragmentation. Neutrons in the energy range from tens to thousands of $\mathrm{MeV}$ are produced and moderated to thermal energy before they reach the interior of the counter which is filled with $\mathrm{BF}_{3}$ and operates as a proportional gas counter. At this low energy level neutrons are adsorbed by boron which splits into ${ }^{7} \mathrm{Li}$ and ${ }^{4} \mathrm{He}$. The kinetic energy of these two ions is dissipated by ionising the gas. The charge impulse induced by these ions is counted.

A man-made neutron monitor therefore records the cosmic-ray flux on-line at a specific site by counting the ionisation events induced by neutrons.

In the case of natural detectors we distinguish between a differential and an integrating type.

\subsection{NATURAL DIFFERENTIAL NEUTRON MONITORS}

The underlying principle is as follows: Again, the information on the cosmic-ray flux is obtained from the interaction of cosmic ray particles with a target element. However, since no on-line recording of the interaction is possible, a memory is required to reliably store this information. The atmosphere serves as counting gas. It contains mainly the elements $\mathrm{N}, \mathrm{O}$, and Ar. Unlike the man-made neutron monitor, it is not the energy released by the interaction that is detected but newly produced nuclei. This has the advantage that, provided these nuclei are properly stored as a function of time, the cosmic-ray flux can be reconstructed by counting the nuclei later. Two important conditions must be fulfilled: firstly, the background must be low which means that we have to choose a type of nucleus which is produced exclusively by cosmic radiation. Radionuclides with half-lives in the range of $10^{3}$ to $10^{6}$ years are, compared to stable nuclides, extremely rare and therefore well suited for this purpose. Table I provides a list of radionuclides produced from $\mathrm{N}$, 


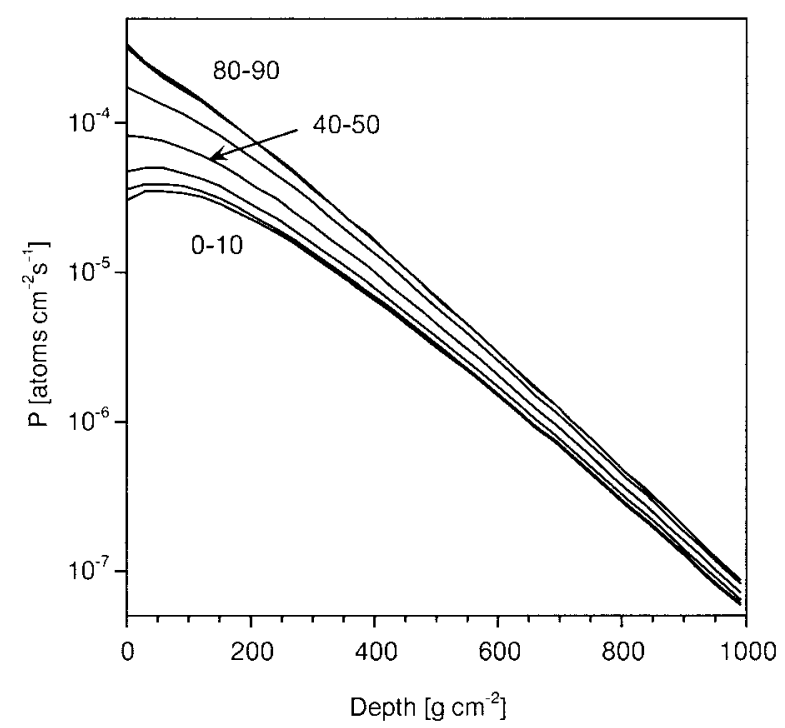

Figure 1. Depth dependent latitudinal production rate of ${ }^{10} \mathrm{Be}$ in the Earth's atmosphere. Each line represents a latitude interval of $10^{\circ}$. The production rate decreases with decreasing latitude for all depths in the atmosphere. For the latitudes $60-90^{\circ}$, the production rate does not change significantly and the lines coincide.

$\mathrm{O}$, and $\mathrm{Ar}$ together with their half-lives, the target elements, and the global mean production rates. The second condition, a memory which collects the produced nuclei as a function of time and stores them undisturbed, is fulfilled by ice sheets and tree rings. All ${ }^{10} \mathrm{Be}$ and part of the ${ }^{36} \mathrm{Cl}$ nuclei become attached to aerosols shortly after they are produced. The rest of ${ }^{36} \mathrm{Cl}$ forms $\mathrm{HCl}$. Within a few years, most aerosols are removed from the atmosphere mainly by wet precipitation. In polar regions they become incorporated into the snow layers formed by each precipitation. These snow layers are compressed by the weight of the overlying layers and finally turn into ice.

${ }^{14} \mathrm{C}$ is oxidised to $\mathrm{CO}_{2}$ and exchanges between atmosphere, ocean, and biosphere. Via photosynthesis, atmospheric ${ }^{14} \mathrm{C}$ is built into tree rings where it can be analysed in annual resolution.

The atmospheric production rate is altitude and latitude dependent. As an example, the production rate of ${ }^{10} \mathrm{Be}$ is shown in Figure 1 as a function of latitude and atmospheric depth (Masarik and Beer, 1999).

The cosmogenic radionuclide flux from the atmosphere into the ice at a specific polar site therefore reflects production changes in the atmosphere but also changes in the exchange rate between stratosphere and troposphere and in the scavenging process from the atmosphere. Especially during climatically unstable periods this can be a problem. A possible means to reduce the climatic noise is to combine several records from different sites. 


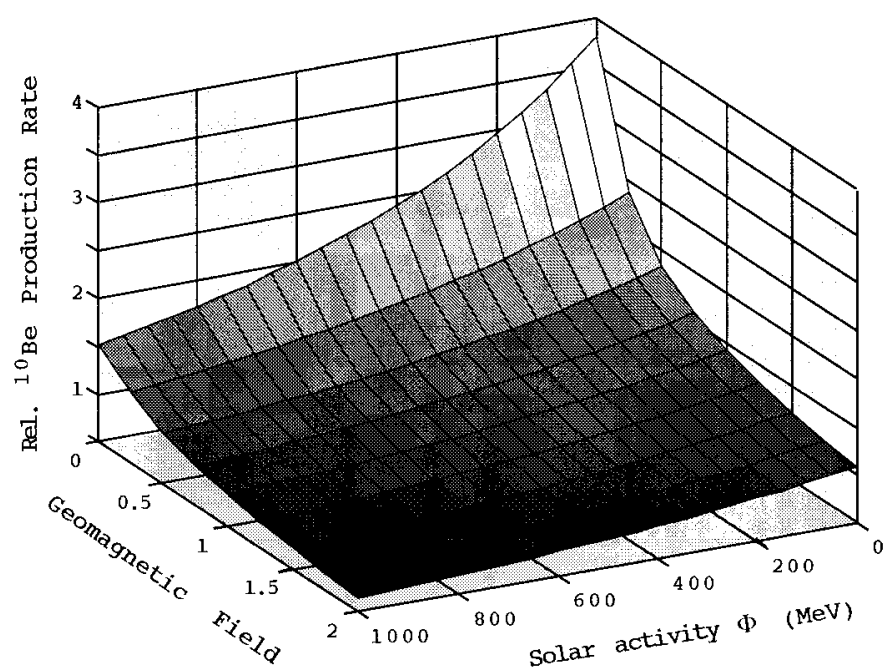

Figure 2. Calculated relative global mean production rate of ${ }^{10} \mathrm{Be}$ in the atmosphere as a function of solar activity expressed by the parameter $\Phi$ and the geomagnetic field intensity relative to its present value. $\Phi=0 \mathrm{MeV}$ corresponds to a quiet Sun, $\Phi=1000 \mathrm{MeV}$ to a very active one. The production rate 1 corresponds to $0.018{ }^{10} \mathrm{Be}$ atoms $\mathrm{cm}^{-2} \mathrm{~s}^{-1}$.

In Figure 2, the global mean production rate of ${ }^{10} \mathrm{Be}$ is shown as a function of solar activity and geomagnetic field intensity. The geomagnetic field intensity and the production rate are given in units relative to the present values. The solar activity is expressed by the parameter $\Phi$ that determines the spectrum of the primary protons (Cini Castagnoli and Lal, 1980). The main differences between this type of natural neutron monitor and man-made monitors are the following:

The monitor does not record the local neutron flux but is representative for a certain part of the atmosphere, the size of which depends on the mixing and transport processes involved. The temporal resolution is limited by the mean atmospheric residence time of about 1 year and also depends on the precision of the dating of the ice.

The interpretation of the cosmogenic nuclide signal is complicated because it is a combination of a production and a transport component.

However, it offers the potential to reconstruct the cosmic-ray history of the last 10000 to 100000 years.

A slightly different qualitative approach was proposed by Dreschhoff and Zeller (1998) to detect solar cosmic-ray events. It is based on mechanisms similar to cosmogenic nuclides. The interaction of cosmic-rays with the atmosphere also produces nitrate that is removed from the atmosphere and stored in polar ice sheets. Since the proton fluxes of such solar events can be very high (fluence: $10^{10}$ protons $\mathrm{cm}^{-2}$ ), but are only of very short duration (hours to days), the transport from the atmosphere into the ice has to be fast and the temporal resolution of the applied analytical technique must be high. According to these authors, both these condi- 


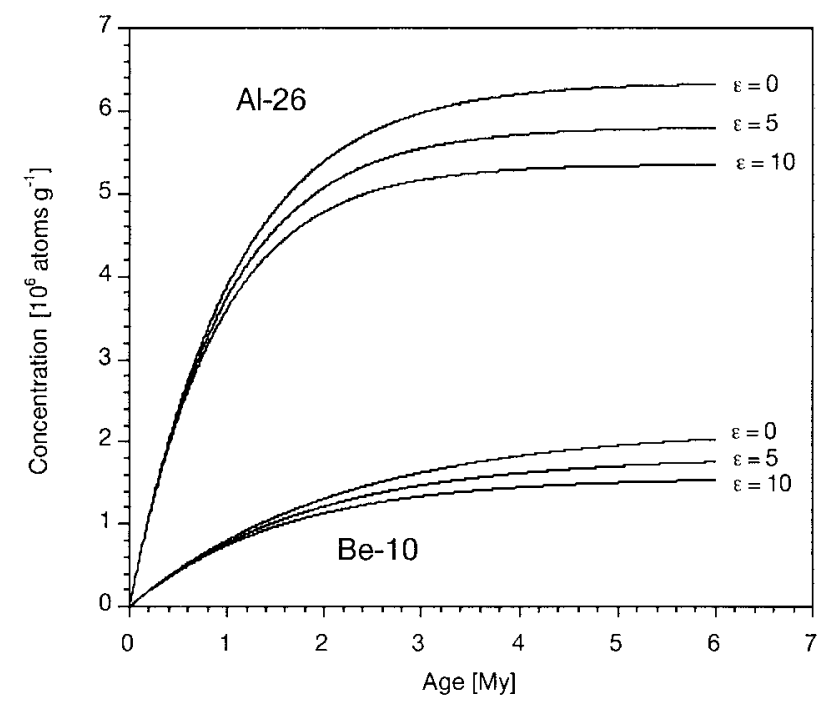

Figure 3. Concentration of ${ }^{10} \mathrm{Be}$ and ${ }^{26} \mathrm{Al}\left(10^{6}\right.$ atoms $\left.\mathrm{g}^{-1}\right)$ in a rock at depth zero as a function of time for different erosion rates $\left(\mathrm{cm} \mathrm{My}^{-1}\right)$ assuming production rates of 1 and 6 atoms $\mathrm{g}^{-1} \mathrm{yr}^{-1}$, respectively.

tions are fulfilled and thus permit them to find signals which can be attributed to known solar proton events (Shea et al., 1999). Other authors were unable to trace such effects (Legrand, 1989).

\subsection{NATURAL INTEGRATING NEUTRON MONITOR OR ROCK NEUTRON MONITOR}

This second type of a natural cosmic-ray monitor is similar to the first one except for two properties: firstly, it is not a gas counter but a solid state detector. Instead of the atmosphere, a rock is used as the medium in which the interaction of cosmicrays takes place. Secondly, since rocks represent closed systems, the radionuclides produced are stored within the rock. This type of detector is therefore operated in an integrating and not in a differential mode. It provides information on the long-term average cosmic-ray flux. The concentration $C$ of a radionuclide as a function of time $t$ and depth $z$ in a rock can be described by the following differential equation:

$$
\frac{\delta C}{\delta t}=P(z)+\varepsilon \frac{\delta C}{\delta z}-\lambda C
$$

with

$$
P(z)=P_{0} e^{-\rho z / \Lambda},
$$

$C$, isotope concentration as a function of depth $z$ in $\mathrm{cm}$ and time $t$ in $y$; $\varepsilon$, erosion rate in $\mathrm{cm} \mathrm{yr}^{-1} ; \lambda$, decay constant in $\mathrm{yr}^{-1} ; P(z)$, production rate in atoms $\mathrm{g}^{-1} \mathrm{yr}^{-1}$; 


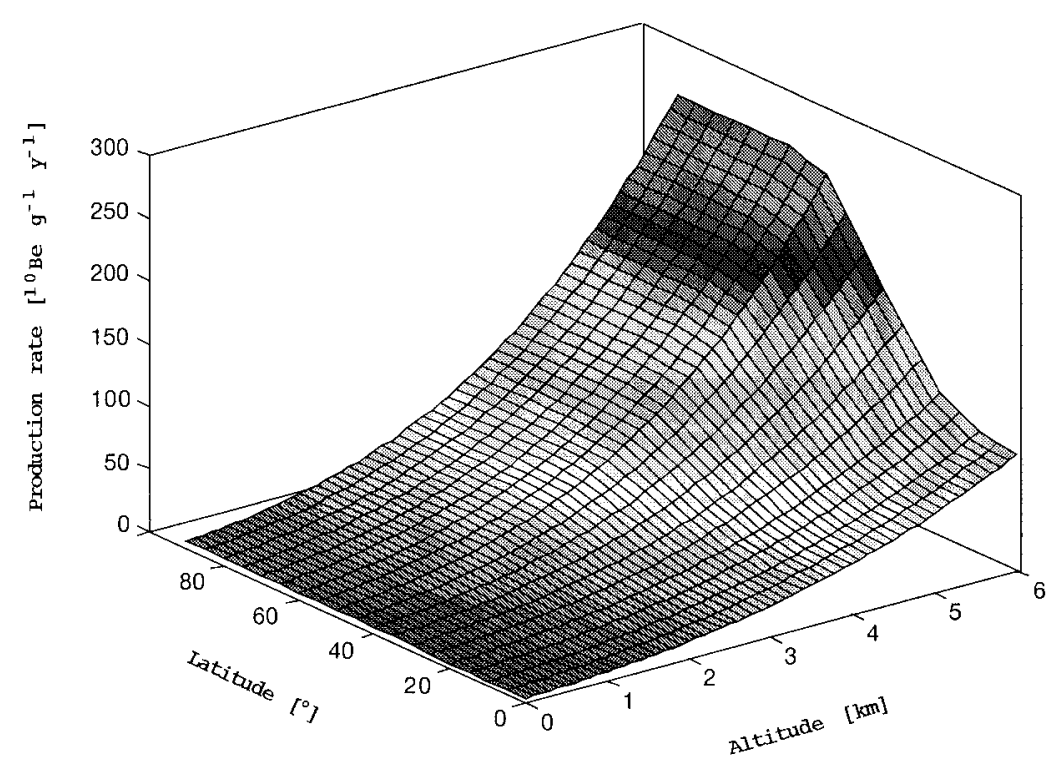

Figure 4. Latitude and altitude dependence of the ${ }^{10} \mathrm{Be}$ production rate (atoms $\mathrm{g}^{-1} \mathrm{yr}^{-1}$ ) in quartz (Lal, 1991).

$P_{0}$, production rate on the surface in atoms $\mathrm{g}^{-1} \mathrm{yr}^{-1} ; \rho$, density in $\mathrm{g} \mathrm{cm}^{-3} ; \Lambda$, production attenuation length in $\mathrm{g} \mathrm{cm}^{-2}$.

If the following assumptions are fulfilled, the differential Equation (1) can be solved analytically:

- The rock in which the production takes place must represent a closed system, e.g., none of the atoms produced should escape nor should any atoms penetrate from outside into the rock.

- $P_{0}, \varepsilon$, and $\Lambda$ are constant.

$$
C(t, z)=\frac{P_{0}}{\rho \varepsilon / \Lambda+\lambda} e^{-\rho z / \Lambda}\left[1-e^{-(\rho \varepsilon / \Lambda+\lambda) t}\right]+C_{0} e^{-\lambda t}+\sum P_{\text {other }}
$$

The first term shows the dependence of the concentration $C$ as a function of depth $z$ and time $t$. The second term describes the concentration $C_{0}$ already present at the time the production starts and $P_{\text {other }}$ summarises all productions other than by cosmic-rays. Formula (3) is also valid for stable isotopes $(\lambda=0)$.

Figure 3 shows the concentration of ${ }^{10} \mathrm{Be}$ and ${ }^{26} \mathrm{Al}$ in quartz $\left(\mathrm{SiO}_{2}\right)$ as a function of exposure time assuming production rates of 1 and 6 atoms $\mathrm{g}^{-1} \mathrm{yr}^{-1}$, respectively, and erosion rates of 0,5 , and $10 \mathrm{~cm} \mathrm{My}^{-1}$. As in the case of the man-made neutron monitor, the production rate depends strongly on the altitude and latitude of the position of the detector (Figure 4).

The main difference, however, is that it only provides integral information. Two approaches are possible to determine the average cosmic-ray flux over a certain 


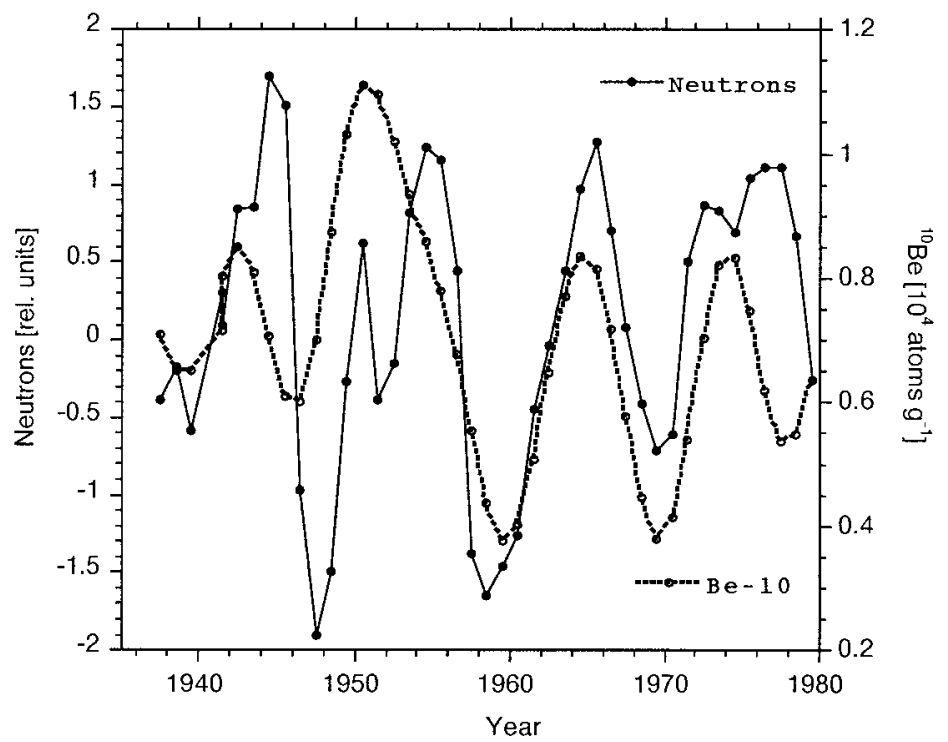

Figure 5. Comparison of a cosmic-ray record composite with data from Cheltenham (1937-1953) and Climax (1953-1980) with the ${ }^{10}$ Be concentration from Dye 3, Greenland (Beer et al., 1994). The ${ }^{10} \mathrm{Be}$ data are shifted by one year to correct for the atmospheric residence time.

time period. Firstly, a radionuclide with an appropriate half-life can be chosen. Secondly, a rock sample can be selected which has been exposed only during a known time period. Such samples can be obtained from rock surfaces which were covered by a glacier that melted away during a climate change, a lake that fell dry or soil that was removed by land slides, volcanic eruptions, impacts of meteorites or by other processes. Important is that the time when the exposure began is well known and that the exposure conditions (surroundings, cover) remained unchanged.

It should be noted that this technique was widely used in the last decades to determine exposure ages of meteorites (Vogt et al., 1990) and more recently also of terrestrial objects (Dorn and Phillips, 1991).

\subsection{Detection of RADiOnUClides}

Finally, the radionuclides stored in ice or rocks have to be extracted and counted. To describe how this is done ${ }^{10} \mathrm{Be}$ is used as an example. As shown in Table I, the global mean production rate of ${ }^{10} \mathrm{Be}$ is 0.018 atoms $\mathrm{cm}^{-2} \mathrm{~s}^{-1}$. Assuming a precipitation rate equal to the global mean of $1000 \mathrm{~mm} \mathrm{yr}^{-1}$, this leads to about $10^{7}$ atoms $\mathrm{kg}^{-1}$ of ice. In the case of rocks the production rate of ${ }^{10} \mathrm{Be}$ in quartz at sea level at the equator is 3.5 atoms $\mathrm{g}^{-1} \mathrm{yr}^{-1}$. Due to the long half-life of ${ }^{10} \mathrm{Be}$ $\left(1.51 \times 10^{6}\right.$ years $)$ decay counting is not suitable. The most sensitive technique today is accelerator mass spectrometry. A small amount (typically $0.5 \mathrm{mg}$ ) of the stable isotope ${ }^{9} \mathrm{Be}$ is added to the sample which results in the presence of $10^{7}{ }^{10} \mathrm{Be}$ 


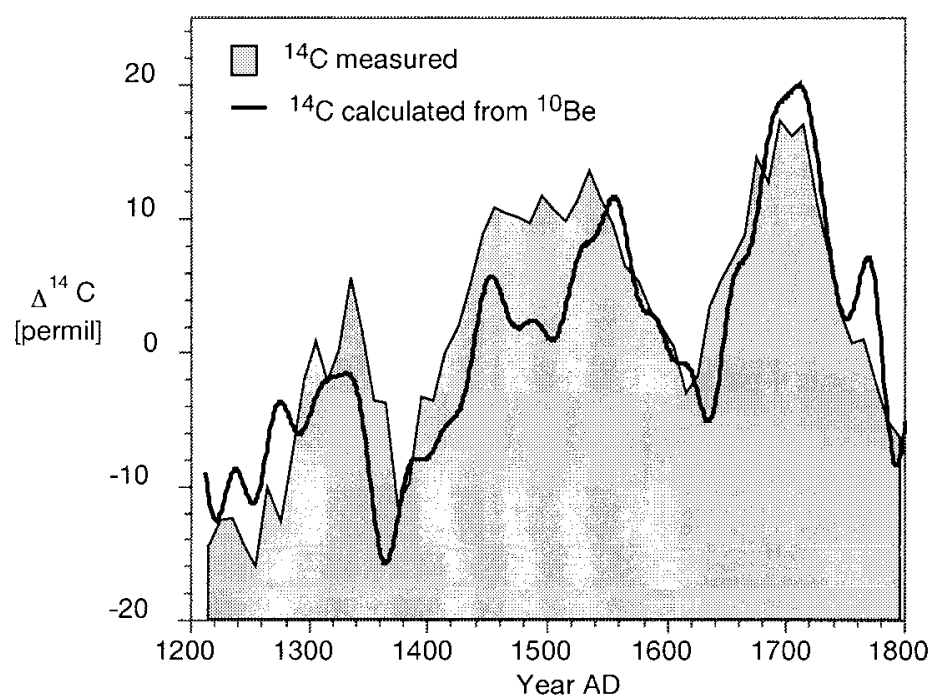

Figure 6. Comparison of the $\Delta{ }^{14} \mathrm{C}$ record measured in tree rings with a $\Delta{ }^{14} \mathrm{C}$ record calculated based on a combined ${ }^{10} \mathrm{Be}$ data set from Greenland (Milcent) and Antarctica (South Pole). The ${ }^{10} \mathrm{Be}$ data have been used as input function for a carbon cycle model to calculate the expected $\Delta{ }^{14} \mathrm{C}$ variations (thick line).

atoms to a ${ }^{10} \mathrm{Be} /{ }^{9} \mathrm{Be}$ ratio in the order of $10^{-13}$ which can be measured with an accuracy of $5-10 \%$.

\section{Applications}

In the following some results are presented to illustrate the performance of the natural cosmic-ray detectors discussed.

\subsection{COSMIC-RAY VARIABILITY ON ANNUAL TO CENTENNIAL TIME SCALES}

The best known variability is the 11-yr Schwabe cycle caused by solar activity. Figure 5 shows a comparison between man-made and natural differential cosmicray detectors. The cosmic-ray record was obtained by combining the Cheltenham ionisation chamber data with the climax neutron monitor data (Beer et al., 1991). They were combined after subtracting the respective mean values and dividing by the standard deviations.

The ${ }^{10} \mathrm{Be}$ concentrations were measured at Dye 3, Greenland, in a shallow ice core of $300 \mathrm{~m}$ length going back to $1423 \mathrm{AD}$ (Beer et al., 1994). After applying a 6-year low pass filter to remove the transport noise, the data were shifted by one year to correct for the atmospheric residence time. A Fourier analysis of the whole Dye $3{ }^{10} \mathrm{Be}$ record shows a strong line at 10.8 years in good agreement with the 


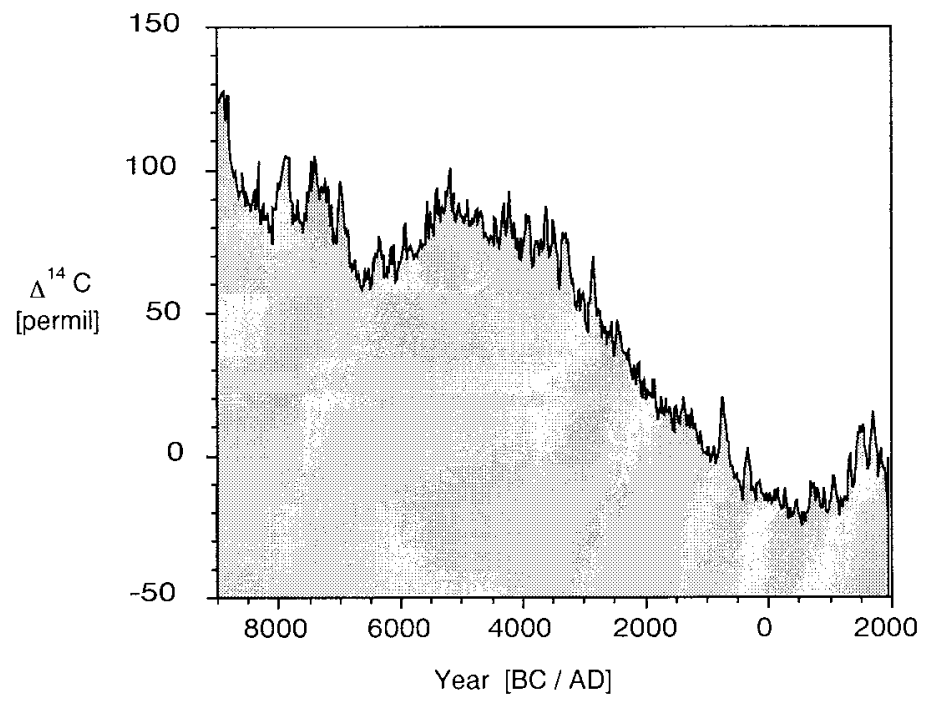

Figure 7. $\Delta^{14} \mathrm{C}$ record measured in tree rings for the last 11000 years. The atmospheric ${ }^{14} \mathrm{C} /{ }^{12} \mathrm{C}$ ratio was most of the time higher than today due to a higher production rate. Note the peaks of typically $70-120$ years duration that indicate periods of low solar activity (e.g., Maunder minimum 1645-1715 AD).

sunspot cycle (Beer et al., 1996). There are also clear indications for the 90 -year Gleissberg cycle (Gleissberg, 1965).

\subsection{CENTURIAL TO MILLENNIAL VARIABILITY}

Moving to variability on time scales of centuries to millennia, longer records of cosmogenic nuclides have to be analysed. In Figure 6 two records of $\Delta^{14} \mathrm{C}$, the per mil deviation of the atmospheric ${ }^{14} \mathrm{C} /{ }^{12} \mathrm{C}$ ratio from the standard value are plotted. The first was obtained by measuring the ${ }^{14} \mathrm{C} /{ }^{12} \mathrm{C}$ ratio in tree rings (Stuiver and Quay, 1980). The second was calculated based on ${ }^{10} \mathrm{Be}$ measurements from ice cores. For this purpose, the ${ }^{10} \mathrm{Be}$ concentration from Milcent, Greenland, and the South Pole were combined (Beer et al., 1991). The resulting record was considered as proxy for the global mean atmospheric production rate. Therefore, it was used as input function for a box diffusion carbon cycle model (Siegenthaler and Beer, 1988) to calculate the corresponding $\Delta^{14} \mathrm{C}$ values.

The good agreement between the measured and the calculated $\Delta^{14} \mathrm{C}$ curves clearly indicates that they are mainly due to production effects that are very similar for both radionuclides and not due to system effects that are completely different for ${ }^{10} \mathrm{Be}$ and ${ }^{14} \mathrm{C}$. The peaks with maxima around 1700, 1500, and $1300 \mathrm{AD}$ correspond to the known intervals of solar minima (Maunder, Spoerer, and Wolf). An analysis of the whole $\Delta^{14} \mathrm{C}$ tree ring record (Figure 7) reveals that the cosmic-ray flux is modulated by the 207 year De Vries cycle. This cycle is also present in the 


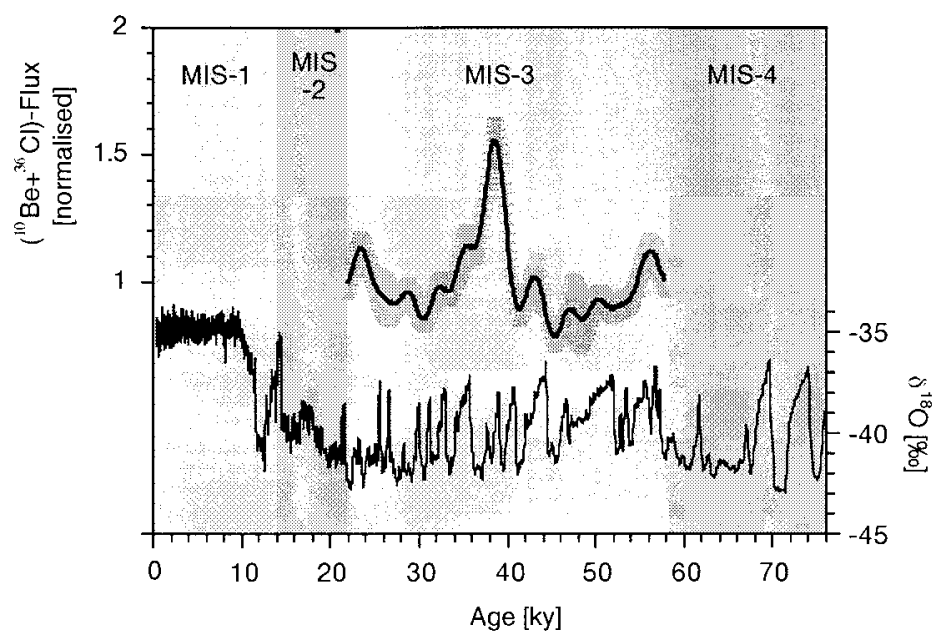

Figure 8. cosmic-ray flux derived from the normalised $\left({ }^{10} \mathrm{Be}+{ }^{36} \mathrm{Cl}\right)$ flux in the GRIP ice core (Wagner, 1998) together with the corresponding $\delta^{18} \mathrm{O}$ values (Dansgaard et al., 1993).

${ }^{10} \mathrm{Be}$ records (not shown here) and indicates the persistence of solar cycles over long times although the amplitudes are low during certain periods.

A periodicity in the range of 2000 to 2500 years is present both in the $\Delta^{14} \mathrm{C}$ record as well as in climatic records. Since no direct solar observations over such long time scales are available it cannot unambiguously be attributed to solar modulation.

\subsection{MillenNiAl AND LONGER Time SCALES}

For very long time scales, geomagnetic and climatic modulation must be taken into account. Large and fast changes in the $\delta^{18} \mathrm{O}$ records in polar ice cores during the last glacial period (10-100 ky PB) point to abrupt climate changes reflected in the temperature and the precipitation rate (Johnsen et al., 1992). Calculating the flux of cosmogenic nuclides should help to remove accumulation effects.

In Figure $8 \delta^{18} \mathrm{O}$ is plotted together with the cosmic-ray flux derived from ${ }^{10} \mathrm{Be}$ and ${ }^{36} \mathrm{Cl}$ measurements in the GRIP ice core (Baumgartner et al., 1996; Yiou et al., 1997) for the marine isotope stage 3 (MIS 3) after applying a low pass filter with a cut off frequency of $1 /(3000 \mathrm{yr})$. Assuming that this flux reflects mainly the production rate modulated by the geomagnetic dipole moment, the field intensity can be derived based on the known relationship between production rate and field intensity shown in Figure 2 and assuming a constant solar activity of $\Phi=550 \mathrm{MeV}$.

The result is presented in Figure 9 (Wagner et al., 2000). A comparison with the magnetic remanence obtained from sediment cores of the Mediterranean sea (Tric et al., 1992) reveals a good agreement. It shows that the cosmic-ray flux varied considerably during the last $100 \mathrm{ky}$ plotted for the marine isotope stage 3. Around 40 ky BP its intensity was strongly increased during a period called the Laschamp 


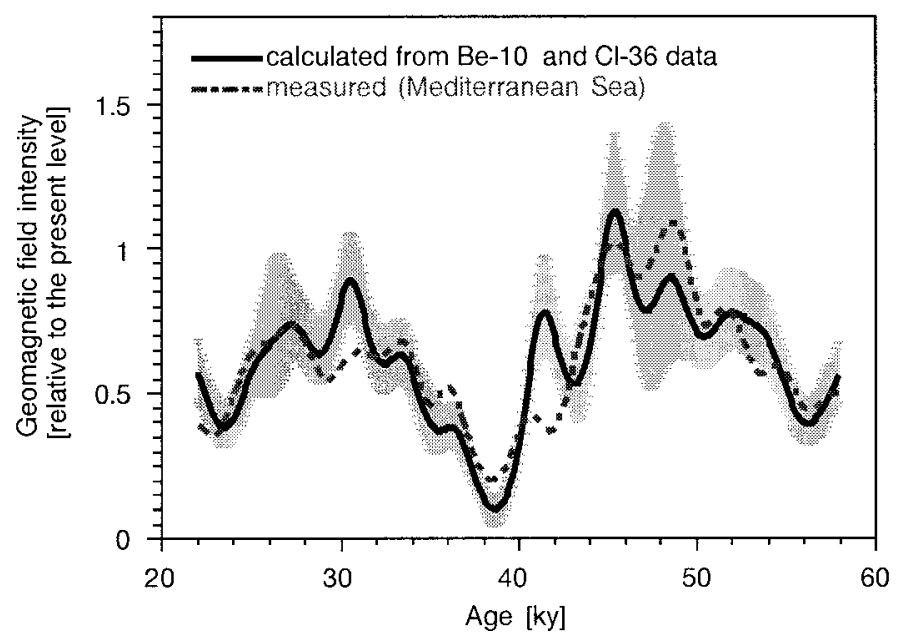

Figure 9. Comparison of the calculated geomagnetic field intensity derived from the cosmic-ray flux in Figure 8 with the field measured in a mediterranean sedi- ment core (shaded area: uncertainty of the calculated field).

event when the geomagnetic field was very weak ( $\sim 10 \%$ of its present value) and almost reversed its polarity. This enhancement in cosmogenic radionuclides was found in several ice cores from both hemispheres (Beer et al., 1992). There were several attempts to explain it as the result of a supernova explosion (Sonett et al., 1987; Kocharov, 1986). However, in view of the consistency between the wellestablished magnetic Laschamp excursion (Vlag et al., 1996) and the cosmogenic nuclide flux this explanation seems rather unlikely.

\section{Conclusions}

Cosmic-rays provide a wealth of information about processes taking place in the cosmos in general and in the vicinity of the Earth in particular on all time scales. Since about half a century this information can be read on-line by man-made neutron monitors. Fortunately, for longer time scales nature provides natural neutron monitors in the form of cosmogenic nuclides that are produced in the atmosphere or rocks and become stored subsequently in ice sheets $\left({ }^{10} \mathrm{Be},{ }^{36} \mathrm{Cl}\right)$, tree rings $\left({ }^{14} \mathrm{C}\right)$ or the rock itself. Today, the sensitivity of analytical techniques and detailed understanding of the relationship between cosmic-ray flux and the production rate of cosmogenic radionuclides enable us to read the information stored and interpret it in terms of changes of the cosmic-ray flux on time scales from years to millennia. 


\section{Acknowledgements}

I am thankful to G. Wagner and E. Flückiger for valuable discussions and providing data and figures, B. Stauffer for reviewing and C. Wedema for correcting the manuscript, and ISSI for organising this workshop. This work was supported by the Swiss National Science foundation.

\section{References}

Baumgartner, S., Beer, J., Dittrich-Hannen, B., Synal, H.-A., Kubik, P. W., Hammer, C., and Johnsen, S.: 1996, 'Chlorine-36 Fallout in the Summit, Greenland Ice Core Project Ice Core', J. Geophys. Res. 102, 26659-26662.

Beer, J., Raisbeck, G. M., and Yiou, F.: 1991, 'Time Variations of ${ }^{10}$ Be and Solar Activity', in C. P. Sonett, M. S. Giampapa, and M. S. Matthews (eds.), The Sun in Time, University of Arizona Press, Tucson, pp. 343-359.

Beer, J., Johnsen, S. J., Bonani, G., Finkel, R. C., Langway, C. C., Oeschger, H., Stauffer, B., Suter, M., and Wölfli, W.: 1992, ' ${ }^{10}$ Be Peaks as Time Markers in Polar Ice Cores', in E. Bard, and W. S. Broecker (eds.), Proc. Erice Nato Workshop. The Last Delegation: Absolute and Radiocarbon Chronologies, Springer-Verlag, Berlin, Vol. 2, pp. 141-153.

Beer, J., Baumgartner, S., Hannen-Dittrich, B., Hauenstein, J., Kubik, P., Lukasczyk, C., Mende, W., Stellmacher, R., and Suter, M.: 1994, 'Solar Variability Traced by Cosmogenic Isotopes', J. M. Pap, C. Fröhlich, H. S. Hudson, and S. K. Solanki (eds.), The Sun as a Variable Star: Solar and Stellar Irradiance Variations, Cambridge University Press, Cambridge, pp. 291-300.

Beer, J., Mende, W., Stellmacher, R., and White, O. R.: 1996, in P.D. Jones, R.S. Bradley, and J. Jouzel (eds.), 'Intercomparisons of Proxies for Past Solar Variability', Climatic Variations and Forcing Mechanisms of the Last 2000 years, NATO ASI I 41, Springer-Verlag, Heidelberg, pp. 501-517.

Cini Castagnoli, G. C. and Lal, D.: 1980, 'Solar Modulation Effects in Terrestrial Production of Carbon-14', Radiocarbon 22, 133-158.

Dansgaard, W., Johnsen, S. J., Clausen, H. B., Dahl-Jensen, D., Gundestrup, N. S., Hammer, C. U., Hvidberg, C. S., Steffensen, J. P., Sveinbjörnsdottir, A. E., Jouzel, J., and Bond, G.: 1993, 'Evidence for General Instability of Past Climate From a 250-kyr Ice-core Record', Nature 364, 218 -220 .

Dorn, R. I. and Phillips, F. M.: 1991, 'Surface Exposure Dating: Review and Critical Evaluation', Physical Geography 12, 303-333.

Dreschhoff, G. and Zeller, E. J.: 1998, 'Ultra-high Resolution Nitrate in Polar Ice as Indicator of Past Solar Activity', Solar Phys. 177, 365-374.

Gleissberg, W.: 1965, 'The Eighty-year Solar Cycle in Auroral Frequency Numbers', J. Br. Astron. Assoc. 75, 227.

Johnsen, S. J., Clausen, H. B., Dansgaard, W., Fuhrer, K., Gundestrup, N., Hammer, C. U., Iversen, P., Jouzel, J., Stauffer, B., and Steffensen, J. P.: 1992, 'Irregular Glacial Interstadials Recorded in a new Greenland Ice Core', Nature 359, 311-313.

Kocharov, G. E.: 1986, 'cosmic-ray Archaeology, Solar Activity and Supernova Explosions', European Space Agency, August 1986, 259-270.

Lal, D.: 1991, 'cosmic-ray Labeling of Erosion Surfaces: In Situ Nuclide Production Rates and Erosion Models', Earth Planetary Sci. Lett. 104, 424-439.

Legrand, M.: 1989, 'A Model Study of the Stratospheric Budget of odd Nitrogen, Including Effects of Solar Variations', Tellus 41B, 413. 
Masarik, J. and Beer, J.: 1999, 'Simulation of Particle Fluxes and Cosmogenic Nuclide Production in the Earth's Atmosphere', J. Geophys. Res. 104, 12 099-13 012.

Shea, M. A., Smart, D. F., and Dreschhoff, G. A. M.: 1999, 'Identification of Major Proton Fluence Events From Nitrates in Polar Ice Cores', Radiation Managements, accepted.

Siegenthaler, U. and Beer, J.: 1988, in F. R. Stephenson and W. Wolfendale (eds.), 'Model Comparison of ${ }^{14} \mathrm{C}$ and ${ }^{10} \mathrm{Be}$ Isotope Records', Secular Solar and Geomagnetic Variations in the Last 10000 Years, Kluwer Academic Publishers, Durham, pp. 315-328.

Sonett, C. P., Morfill, G. E., and Jokipii, J. R.: 1987, 'Interstellar Shock Waves and ${ }^{10}$ Be from Ice Cores', Nature 330, 458-460.

Stuiver, M. and Quay, P. D.: 1980, 'Changes in Atmospheric Carbon-14 Attributed to a Variable Sun', Science 207, 11-19.

Tric, E., Valet, J. P., Tucholka, P., Paterne, M., LaBeyrie, L., Guichard, F., Tauxe, L., and Fontugne, M.: 1992, 'Paleointensity of the Geomagnetic Field During the Last 80000 years', J. Geophys. Res. 97, 9337-9351.

Vlag, P., Thouveny, N., Williamson, D., Rochette, P., and Ben-Atig, F.: 1996, 'Evidence for a Geomagnetic Excursion Recorded in the Sediments of Lac St. Front, France: A Link With the Laschamp Excursion', J. Geophys. Res. 101, 28 211-28 230.

Vogt, S., Herzog, G. F., and Reedy, R. C.: 1990, 'Cosmogenic Nuclides in Extraterrestrial Materials', Rev. Geophys. 28, 253-275.

Wagner, G.: 1998, Die kosmogenen Radionuklide Be-10 und Cl-36 im Summit-GRIP-Eisbohrkern, ETH-Zürich, Zürich.

Wagner, G., Masarik, J., Beer, J., Baumgartner, S., Imboden, D., Kubik, P. W., Synal, H.-A., and Suter, M.: 2000, 'Reconstruction of the Geomagnetic Field Between 20 and 60 ka From Cosmogenic Nuclides in the GRIP Ice Core', Nucl. Instr. Meth., accepted.

Yiou, F., Raisbeck, G. M., Baumgartner, S., Beer, J., Hammer, C., Johnsen, S., Jouzel, J., Kubik, P. W., Lestringuez, J., Stiévenard, M., Suter, M., and Yiou, P.: 1997, 'Beryllium-10 in the Greenland Ice Core Project Ice Core at Summit, Greenland', J. Geophys.Res. 102, $26783-$ 26794.

Address for Offprints: Jürg Beer, Environmental Physics, EAWAG, Überlandstrasse 133, CH-8600

Dübendorf, Switzerland; Beer@eawag. ch 